\title{
Details and picture recall
}

\author{
RUSSELL G. COULTER, MARCIE L. COULTER, and JOHN A. GLOVER \\ University of Nebraska, Lincoln, Nebraska
}

Five conditions varied the amount of pictorial detail in drawings presented to subjects. Analysis of free-recall data suggests that the intention of subjects determines their levels of recall to a great extent. The results did not support an effort hypothesis.

Research on the comparative memorability of visual stimuli of differing levels of detail has led to inconsistent and sometimes conflicting findings. For example, Nelson, Metzler, and Reed (1974) presented pictures that varied along a continuum of detail (from unembellished line drawings to photographs) to subjects for a later recognition task. Their results indicated no significant difference in recognition of the types of pictures at either immediate testing or testing after a 1-week delay (Nelson et al., 1974). In contrast, Loftus and Bell (1975) employed the Nelson et al. materials and found that recognition of photographs was significantly superior to the recognition of either unembellished line drawings or embellished line drawings.

The results of studies that have employed free recall of stimulus arrays as their dependent measure have, if anything, been more confusing. Denis (1976) compared recall of black-and-white or colored drawings with and without detail and found that the recall of detailed colored drawings was significantly superior to the recall of undetailed black-and-white drawings. Peeck, van Dam, and Uhlenbeck (1977) found no difference in the recall of black-and-white "enriched" and "impoverished" drawings. In a later study, Peeck and van Dam (1978) found that the recall of photographs of complex scenes did not differ from the recall of photographs of simple objects. Finally, Ritchey (1982), in an attempt to clarify some of the problems in earlier research, compared oral recall of the names of items, outline drawings of items with their names accompanying them, and line drawings of objects with their names accompanying them. Furthermore, the stimuli were presented to subjects of different ages in two sets, one chosen to minimize categorization, the other with six clearly identifiable categories. In addition to finding significant differences by age and condition (categorized/noncategorized), the outlines were recalled at a significantly greater rate than either the line drawings or the names alone in the noncategorized condition.

As Ritchey (1982) pointed out, there are several difficulties in evaluating the studies in this area. First, several different kinds of stimulus presentation ap-

Requests for reprints should be sent to John A. Glover, Department of Educational Psychology, University of Nebraska, Lincoln, Nebraska 68588-0440. proaches have been employed (e.g., drawings alone, drawings with names, colored pictures vs. black and white). Second, only three studies have employed stimuli on a continuum of detail. Third, both recognition and recall measures have been employed. Fourth, no consistent theoretical perspective has been employed as the heuristic for the research, although, on occasion, variants of an elaboration hypothesis (e.g., Craik \& Tulving, 1975) have been offered as explanations.

The purpose of the current study was to replicate Ritchey's (1982) study and, it was hoped, to clarify further the problems Ritchey had addressed earlier. Specifically, it seemed to us that an 'effort"' hypothesis (e.g., Auble, Franks, \& Soraci, 1979) might prove to be a more fruitful heuristic from which to proceed than would an elaboration hypothesis. In our view, sparse stimulus arrays such as outline drawings require subjects to engage in more effortful processing and, in this manner, form more distinctive memory traces. Therefore, we predicted that recall of stimulus arrays would increase as the detail present in the arrays decreased. Another issue, however, was also addressed in the current study. Ritchey employed drawings with the names of the objects appearing immediately below them. In such conditions, it is conceivable that subjects could form both a memory trace of the visual array and access their semantic memories for the names. In general, we would expect the same progression of recall from greatest to least on the basis of the sparcity of detail. We predicted, however, that, because of a potentially lower level of needed effort, the recall of items presented along with the names of the items would be lower than that of drawings of items presented alone. Last, we also determined to perform two separate analyses of the data such that subjects who anticipated the recall task were included in one analysis but not in the second.

\section{METHOD}

\section{Subjects and Setting}

The subjects, who participated for course credit, were 75 undergraduates from two midwestern institutions. All testing occurred in classrooms over a period of 6 weeks.

\section{Materials and Design}

A set of 30 common items was selected, and each item was prepared in five formats: (1) detailed drawing, (2) outline drawing, (3) detailed drawing with name label, (4) outline drawing 
Table 1

Recall of Pictures

\begin{tabular}{|c|c|c|c|c|c|c|}
\hline \multirow[b]{2}{*}{ Condition } & \multicolumn{3}{|c|}{ First Analysis } & \multicolumn{3}{|c|}{ Second Analysis } \\
\hline & $\mathbf{N}$ & Mean & SD & $\mathbf{N}$ & Mean & SD \\
\hline Name Labels Only & 15 & 12.93 & 4.53 & 9 & 10.22 & .67 \\
\hline Detailed Pictures & 15 & 14.47 & 3.25 & 9 & 13.44 & 3.24 \\
\hline Detailed Pictures With Labels & 15 & 14.93 & 2.91 & 10 & 13.70 & 2.41 \\
\hline Outlines With Labels & 15 & 14.33 & 2.44 & 10 & 13.90 & 1.85 \\
\hline Outlines Only & 15 & 16.47 & 3.98 & 9 & 16.44 & 3.94 \\
\hline
\end{tabular}

with name label, and (5) name label only. Each drawing and/or name label was placed on an $11 \times 14 \mathrm{~cm}$ card. On those cards on which both drawings and name labels appeared, the drawings were centered on the cards and the name labels appeared on the bottom right-hand side. On those cards on which only a name label appeared, the name label was centered and was presented in large, block letters. The drawings were pretested on a pilot group of 15 subjects in order to assure clarity. Each subject in the study was presented with one of the sets of 30 items. The subjects were assigned randomly to formats.

\section{Procedure}

The subjects were tested individually. The instructions were simply to watch the cards. Before presentation of the cards, the subjects were asked general questions about age, class, and so on. The posttest was not mentioned. The experimenter presented the cards to the subjects at a distance of approximately $75 \mathrm{~cm}$. Each card was presented for 4 sec. Following the recall task, the subjects were asked whether they had anticipated a test over the materials. Following a $20-\mathrm{sec}$ break, the subjects were given 5 min for oral recall.

\section{RESULTS}

Two separate analyses of the recall data were performed. First, the data from all 75 subjects were analyzed via a simple univariate analysis of variance, which indicated no significant difference among the conditions $[F(4,70)=1.97, p>.10]$ (see Table 1 ). Then only the data from the protocols of the 47 subjects who indicated that they had not anticipated the posttest were reanalyzed. The results of the second analysis revealed a significant difference among the conditions $[F(4,42)=$ 6.27, $\mathrm{p}<.01$ ] (see Table 1).

The Tukey HSD procedure $(\alpha=.05)$ indicated that the outline-only condition resulted in recall significantly superior to that of the name-label-only condition. In addition, the detailed-drawing-only condition and the outline-with-name-label condition resulted in recall significantly superior to that of the name-label-only condition. Finally the detailed-drawing-with-name-label condition resulted in recall significantly better than that of the name-label-only condition. No other contrasts reached significance.

\section{DISCUSSION}

The results did not confirm our hypothesis that the amount of recall would be inversely related to the amount of detail presented in the figures. However, in the second analysis, the outline-only condition did result in recall significantly better than that of the name-label condition and better, although not significantly better, recall than that of the detailed-drawing condition. The presence of a name label seemed to have a deleterious effect on recall in the outlinewith-name-label condition, as would be expected if an increase in information would result in poorer recall. However, given the nearly equal levels of recall in the detailed-drawing-only and the detailed-drawing-plus-name-label conditions, the name labels seemed to have no effect on the recall of detailed drawings.

In general, the results also confirm Ritchey's (1982) finding of superior recall in the outline-only condition. It must be pointed out, however, that our data indicated differences only in our planned second analysis, in which the data from subjects who had anticipated the purpose of the study and had attempted to memorize the stimulus arrays were deleted.

Overall, it seems that the current results do less to answer questions than they do to raise them. First, our "effort" hypothesis was not substantiated. In our view, this raises the issue of how to quantify pictorially presented information. That is, what is an appropriate unit of pictorial information, and how can measures of pictorial information be related to the amount of information presented in a name label? It seems that, until some set of such measures can be agreed upon, there is very little purpose in continuing to demonstrate that some pictures are or are not better remembered than others. And, although an "effort" hypothesis may not be valid, elaboration and distinctiveness hypotheses, to be fully tested, also require the quantification of information in pictures. Second, comparing subjects' recall of name labels with their recall of pictures (or combinations of them) may be another way of comparing apples and oranges. In our view, at least, whether pictures and words are processed in the same or in different ways is unclear. Third, it seems that the intentions of subjects who are presented materials determine to a large extent what those subjects recall. The 28 subjects excluded from our second analysis generally had very high recall scores. Fourth, the extremely high withingroup variance observed in both the first and the second analysis suggests that some rather powerful individual differences were at work, differences that future research may need to take into account. Other problems, amply described by Ritchey (1982), also need to be resolved.

\section{REFERENCES}

Auble, P. M., Franks, J. J., \& Soraci, S. A. (1979). Effort toward comprehension: Elaboration or "aha!"? Memory \& Cognition, 7, 426-434.

Craik, F. I. M., \& Tulving, E. (1975). Depth of processing and the retention of words in episodic memory. Journal of Experimental Psychology: General, 104, 268-284.

Denis, M. (1976). Test of the incidental-cues hypothesis. Perceptual and Motor Skills, 43, 175-178.

LofTus, G. R., \& Bell, S. M. (1975). Two types of information in picture memory. Journal of Experimental Psychology: Human Learning and Memory, 104, 103-113. 
Nelson, T. O., Metzler, J., \& Reed, D. A. (1974). Role of details in the long-term recognition of pictures and verbal descriptions. Journal of Experimental Psychology, 102, 184-186.

Peeck, J., \& van Dam., G. (1978). Recall of complex and simple pictures in mixed and unmixed lists. Perceptual and Motor Skills, 45, 570.

Peeck, J., van Dam, G., \& Uhlenbeck, R. W. F. (1977). In- cidental cues and picture/word differences in recall. Perceptual and Motor Skills, 45, 1211-1215.

Ritchey, G. H. (1982). Pictorial detail and recall in adults and children. Journal of Experimental Psychology: Learning, Memory, and Cognition, 8, 139-141.

(Manuscript received for publication March 8, 1984.) 